\title{
COUNTERPOINT: Access to transcatheter aortic valve replacement should not be limited to high-volume surgical centers
}

\author{
Philip Green, MD, Gregg F. Rosner, MD, Martin B. Leon, MD, and Allan Schwartz, MD
}

See related articles by Robert Sade on pages $1439-40$ and Joseph E. Bavaria on pages 1441-3.

Transcatheter aortic valve replacement (TAVR) has transformed the treatment of aortic stenosis in high-risk older adults in Europe and has begun to do so in the United States. Recent Food and Drug Administration approval of the Edwards Lifesciences SAPIEN Transcatheter Heart Valve (Irvine, Calif) in inoperable and high-risk patients led to enthusiasm for widespread implementation of this technology. Experts have highlighted the central role of the multidisciplinary heart team in implementing a successful TAVR program. ${ }^{1}$ Other experts, such as Joseph Bavaria, have suggested that access to TAVR should be restricted to high-volume surgical aortic valve replacement centers. In our opinion, access to TAVR should not be limited to high-volume surgical centers for the following reasons. First, high surgical volume does not ensure good outcomes in complex interventional procedures. Second, centers with low or no surgical volume can have excellent interventional results. Third, new multidisciplinary heart teams have achieved excellent results in part because of the transmission of accumulated knowledge from experienced centers. Finally, in the absence of evidence suggesting that highvolume surgical centers produce superior TAVR results, therapeutic options for patients should not be limited.

\section{HIGH SURGICAL VOLUME DOES NOT ENSURE GOOD INTERVENTIONAL OUTCOMES}

The Synergy between Percutaneous Coronary Angioplasty with Taxus and Cardiac Surgery (SYNTAX) trial ${ }^{2}$ randomized 1800 patients with multivessel disease across

\footnotetext{
From the Division of Cardiology, Department of Medicine, Columbia University Medical Center, New York, NY.

Disclosures: Martin B. Leon is a nonpaid member of the Scientific Advisory Board of Edwards Lifesciences. The other authors have nothing to disclose with regard to commercial support.

Read at the 92nd Annual Meeting of The American Association for Thoracic Surgery, San Francisco, California, April 28-May 2, 2012.

Received for publication Feb 25, 2013; accepted for publication Feb 27, 2013.

Address for reprints: Allan Schwartz, MD, Division of Cardiology, Department of Medicine, Columbia University Medical Center, New York Presbyterian Hospital, 177 Fort Washington Ave, Milstein Building, Room 5-435, NY 10032 (E-mail: as20@columbia.edu).

J Thorac Cardiovasc Surg 2013;145:1444-5

0022-5223/\$36.00

Copyright (c) 2013 by The American Association for Thoracic Surgery

http://dx.doi.org/10.1016/j.jtcvs.2013.02.079
}

sites in 17 countries. Participants were randomized to coronary artery bypass surgery or a Taxus stent (Boston Scientific Corporation, Natick, Mass) implantation. Analysis of rates of major adverse cardiac events by site showed that there was no relationship between volume and outcomes for both the Taxus stent and coronary bypass arm of the trial. This indicates that high volume, surgical or percutaneous, does not guarantee excellent outcomes and therefore volume alone should not be treated as a sufficient marker of high-quality care.

\section{CENTERS WITH LOW OR NO SURGICAL VOLUME CAN HAVE EXCELLENT INTERVENTIONAL RESULTS}

Recent data from the Cardiovascular Patient Outcomes Research Team-Elective Angioplasty Study (CPORT-E) trial confirmed that surgical backup is not necessary for excellent interventional outcomes. ${ }^{3}$ In the CPORT-E study, approximately 1900 patients were randomized to percutaneous coronary intervention with surgery on site versus no surgery onsite. The overall 6-week and 9-month adverse cardiac event rates were low and there were no significant differences between the sites with and without surgical backup. These findings underscore the belief that high surgical volume is not essential for excellent interventional cardiology results.

\section{GROUP LEARNING CAN ATTENUATE THE LEARNING CURVE}

Data from the Columbia HeartSource experience have shown that high-volume centers of excellence can transmit expertise to outlying centers. This can be achieved through targeted physician recruitment, a focus on continuous quality improvement through regular oversight and peer review, and formal and informal didactics. Most importantly, expert consultation is available to all participating sites at all times, including nights and weekends. The use of this approach to transmit knowledge across sites has enabled low-volume sites to achieve cardiac surgical risk-adjusted outcomes that are comparable with high-volumes affiliates. ${ }^{4}$

This group-learning phenomena has been replicated on a larger scale in the transcatheter arena in Europe and in the United States. In the European Edwards SAPIEN Aortic Bioprosthesis European Outcome (SOURCE) Registry, the early (January 2008 to January 2009; $\mathrm{n}=575$ ) and later (February 2009 to January 2010; $\mathrm{n}=819$ ) transapical TAVR results were compared. Despite comparable baseline 
risk characteristics, outcomes in the early group were as good as outcomes in the later group. Specifically, there were no differences in 30-day rates of death, stroke, bleeding, or vascular complications. ${ }^{5}$ The absence of a demonstrable learning curve is a result of shared knowledge across sites, enabling each site to rapidly integrate the collective experience to achieve results comparable with more experienced sites. The early US TAVR experience also showed that group learning can attenuate the learning curve. Dewey and colleagues (STS presentation; January, 2012) analyzed the randomized and nonrandomized continued-access transfemoral TAVR Placement of Aortic Transcatheter Valve (PARTNER) trial experience and showed the following: (1) 30-day and 1-year mortality rates among the TAVR subjects were not different when high-enrolling sites were compared with low-enrolling sites, and (2) the 30-day and 1 -year mortality rates were similar for the first set of 20 , the second set of 20, and the third set of 20 valve implantations at each site (PARTNER Executive Committee presentation; April, 2012). This suggests that early lessons learned were integrated rapidly into the group experience and through formal and informal educational initiatives and hands-on proctoring, excellent results were achieved in low-volume sites and among the first cases at new sites.

Finally, although we applaud the careful assimilation of TAVR technology to clinical care to ensure optimal outcomes for the highest-risk patients, restricting this kind of therapy to centers with high surgical aortic valve replacement volume is unprecedented in the surgical community. Bolling and colleagues ${ }^{6}$ highlighted that most mitral valve surgery occurs at low-volume sites, despite the increased likelihood of successful mitral valve repair at highvolume centers. Furthermore, Dewey and colleagues ${ }^{7}$ showed that the discordance between observed and expected outcomes after aortic valve replacement decreases as surgical volume increases. However, according to data from the Society of Thoracic Surgery database, the median number of sole aortic valve replacements per center is 20 per year, and per cardiac surgeon is 8 per year (Society of Thoracic Surgery database; 2010). Despite evidence of better outcomes at high-volume surgical centers, heart valve surgery is not restricted to high-volume centers. In TAVR, in which the available evidence suggests that an excellent heart team with the support of national experts and regional centers can achieve excellent results despite low volume, there is no rationale to restrict the availability of this transformative technology to patients cared for at high-volume surgical centers.

\section{References}

1. Holmes DR Jr, Mack MJ, Kaul S, Agnihotri A, Alexander KP, Bailey SR, et al. 2012 ACCF/AATS/SCAI/STS expert consensus document on transcatheter aortic valve replacement. J Am Coll Cardiol. 2012;59:1200-54.

2. Serruys PW, Morice M-C, Kappetein AP, Colombo A, Holmes DR, Mack MJ et al. Percutaneous coronary intervention versus coronary-artery bypass grafting for severe coronary artery disease. N Engl J Med. 2009;360:961-72.

3. Aversano T, Lemmon CC, Liu L. Outcomes of PCI at hospitals with or without onsite cardiac surgery. N Engl J Med. 2012;366:1792-802.

4. Kurlansky PA, Argenziano M, Dunton R, Lancey R, Nast E, Stewart A, et al. Quality, not volume, determines outcome of coronary artery bypass surgery in a university-based community hospital network. J Thorac Cardiovasc Surg. 2012;143:287-93.e281.

5. Wendler O, Walther T, Schroefel H, Lange RD, Treede H, Fusari M, et al. The SOURCE Registry: what is the learning curve in trans-apical aortic valve implantation? Eur J Cardiothoracic Surg. 2011;39:853-60.

6. Bolling SF, Li S, O'Brien SM, Brennan JM, Prager RL, Gammie JS. Predictors of mitral valve repair: clinical and surgeon factors. Ann Thorac Surg. 2010;90: 1904-12.

7. Dewey TM, Herbert MA, Ryan WH, Brinkman WT, Smith R, Prince SL, et al. Influence of surgeon volume on outcomes with aortic valve replacement. Ann Thorac Surg. 2012;93:1107-13 